\title{
A health of man in aspect of evolution
}

\begin{abstract}
It is problem in front of mankind, the significance of which is not yet sufficiently aware neither the public nor the science - biological degradation of the species Homo sapiens. It is an accelerated rate of aging, reducing the number of "health"(viability), the epidemic of chronic non - infectious diseases, reduced reproductive capacity, the birth of a weaker offspring, etc. All this is a consequence of the reduced stability of non - equilibrium thermodynamic system (live) on the grounds of "mitochondrial failure" at the present stage of social evolution. The ways of decision of problem are shown.
\end{abstract}

Keywords: evolution, chronic non-infectious diseases, the pace of ageing, mitochondrial insufficiency, demographic transition
Volume 7 Issue 2 - 2020

\section{Apanasenko GL}

Department of Physical and Rehabilitation Medicine of the National Medical Academy of Postgraduate Education the Name of PI Shupik, Ukraine

Correspondence: Apanasenko AL, Department of physical and rehabilitation medicine of the National medical academy of postgraduate education the name of P L Shupik, Kyiv, Ukraine, Emailapanas@ukr.net

Received: March 20, 2020 | Published: June 30, 2020

\section{Introduction}

There are all grounds to assert that humanity degenerates as a biological kind. Already a few enerations are free of natural selection, and it means that every subsequent generation is weaker than previous. That is about it the largest specialist talks in area of evolution of man A. Markov. ${ }^{1}$ Degeneration in the conditions when there is not a natural selection, takes place quickly and inevitably. Very soon we will get a generation so weak, sickly, sickly and powerless, that no supermodern medicine will help. Solid arguments for proof of the outspoken position are got by us at research of problem of individual health of man. In addition to thermodynamics conception of life to the ground of that works of Bauer $\mathrm{E}^{2}$ were devoted, Schrodinger $\mathrm{E}^{3}$ we clearly set forth thermodynamics conception of health. ${ }^{4,5}$ If life thermodynamics non-equilibrium state is the basis of, then the degree of stability of this non-equilibrium state can be used for the quantitative estimation of viability, or amount of health. Theoretical bases. Thus, a criterion that can be fixed in basis of measuring of health was marked. At organism level this criterion (energypotential of the biosystem) can be described by maximal aerobic possibilities - power and efficiency of aerobic energy, that, in turn, reflect functional possibilities of vehicle of mitochondries. All forms of adaptation are related to the expense of energy of cage. ${ }^{6}$ Thus most exogenous factors (industrial contamination, nicotine, alcohol, etc.) result in suppression of energy of cage and only optimal for an individual physical activity conduces to her growth (similarly as well as hypoxic training).

Getting in a few dissertations of our students reliable data about the catastrophic decline of health level(«amounts»), and also parallel speed-up rate of aging of student young people of Ukraine (Figure 1), we these data published, but did not hurry to parade, supposing that it is clean the post-soviet phenomenon. But the results of research of the Dutch National institute of public health and environment appeared recently, it is shown in that appearance of «senile» illnesses for modern Dutch youth registers oneself on the average on 15 before, than for their grandmothers and grand-dads (13). Rate of aging (grades 1-5) of students of 20-24. Aging grades:
1. Very subzero
2. Subzero
3. Optimal
4. Speed-up

5. Extraordinarily speed-up on a y-axis - \% entering a group, for abscise axis - aging grades A conclusion is based on the results of research with participation 6 thousand adults in age 20,30, 40 and 50 (research overcame a 25 -years-old period).

Analysing their state of health, researchers set that at the young generation a weak «metabolic health» is marked. This term, unfortunately, explains nothing. More logical to talk about «mitochondrial insufficiency», i.e. a power function of mitochondries is below than the limit, conditioned by a biological evolution, what is direct reason of quick ageing (Figure 2).

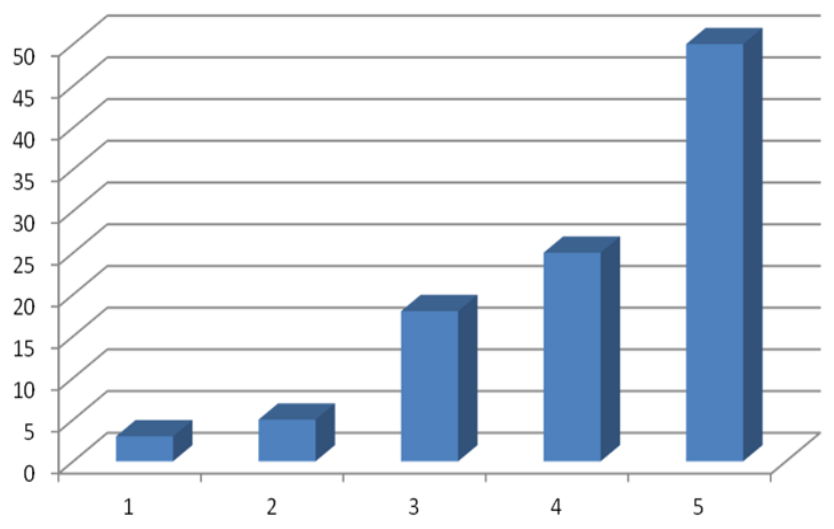

Figure I Rate of aging (grades I-5) of students of 20-24.Aging grades: I- very subzero, 2-subzero, 3-optimal; 4-speed-up, 5-extraordinarily speed-up on a $y$-axis - \% entering a group, for abscise axis-aging grades.

\section{Discussion}

Our conclusion is confirmed by the solid researches conducted in the institute of gerontology of NAMN of Ukraine. ${ }^{8}$ It is set that between functional age and maximal consumption of oxygen (MCO) of individual there is the close dependence described by the coefficient of correlation 0,840 for men and 0,813 for women. It is the last years got convincing enough proofs of validity of «power conception» of health. So, group of the Norwegian researchers, ${ }^{9}$ inspecting more than 4600 practically healthy men and women, marked that with the index of MOC/of $\mathrm{kg}$ of mass $/ \mathrm{of}$ mines below $35 \mathrm{mls}$ in 5 times, and for men below $44 \mathrm{mls} / \mathrm{of} \mathrm{kg} /$ of mines in 8 times more often meet risk of development of cardiovascular diseases (Our criteria of «safe 
health level», set 25 back, - 35 and $42 \mathrm{mls} / \mathrm{of} \mathrm{kg}$ of mass/of mines accordingly) factors. Thus every decline of specific MOC on 5 mis is accompanied by the increase of expressed and prevalence of risk of cardiovascular morbidity factors on $56 \%$. The discussed dependence finds the reflection and in a clinic. Keteyian ${ }^{10}$ showed that every increase of specific MOC on a $1 \mathrm{ml}$ was accompanied by the decline of risk of death and women with IHD on $15 \%$. Myers of and other mark that increase of maximal aerobic ability on 1 MET accompanied by the increase of survivability of men with cardiovascular diseases on $12 \%$. It is shown in other researches, that length of telomeres, lifespan follows with that, is straight proportional $(\mathrm{r}=0,78)$ to maximal aerobic possibilities of individual. ${ }^{11}$ Which is a dynamics of this index at the Ukrainian population? It is set that now only an about $1 \%$ population is in the "safe zone» of health (id est on the step of biopower stair of evolution). 25 back this index made $8 \%$. It is basis of depopulation and quick ageing, that take place not only in Ukraine but also other countries of post-soviet space and Europe. The same dynamics of potential of energy is observed and in the USA. Using the materials of population researches of maximal aerobic ability, got in different years, it is possible to mark important conformity to law, touching biological nature of modern man: for the last 40-50 the population level of maximal aerobic ability substantially went down and on the average goes out outside the "safe zone» of somatic health (Figure 2). Coming from foregoing, there are all grounds to suppose that herein and direct reason of epidemic of chronic uninfectious diseases, staggering the industrially developed countries from the second half of the XX century, consists. (Figure 2) Dynamics of indexes of MCO on the ten - years periods of life in the population of men of the USA from 1939 to 1968 (Andersen K.L., a.o., 1978). «БУЗ« - is a «safe health level» But as does a brain behave?

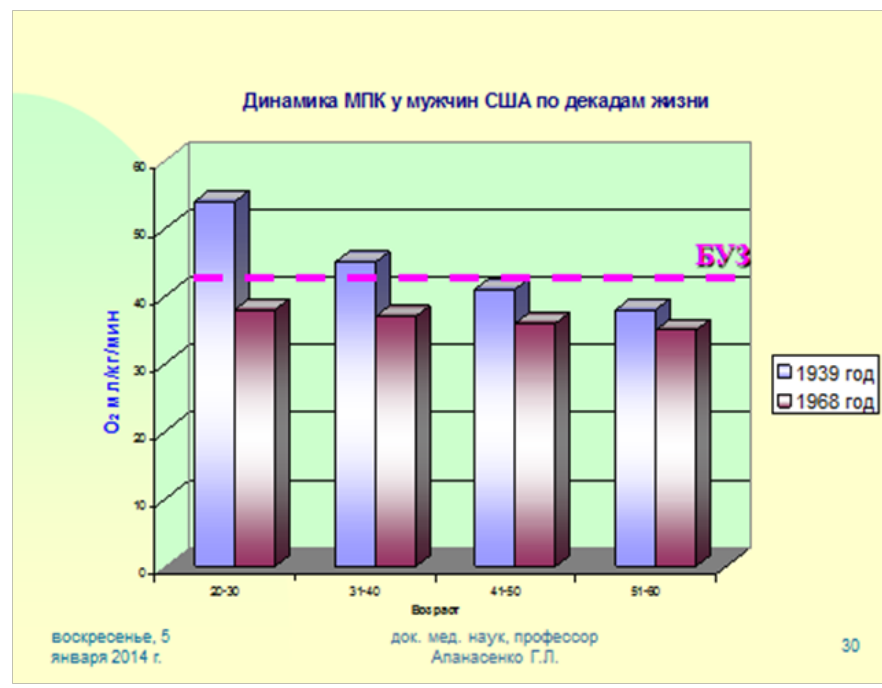

Figure 2 Dynamics of indexes of MCO on the ten - years periods of life in the population of men of the USA from 1939 to 1968 (Andersen K.L., a.o., 1978).

The features of his functioning consist in that he chooses the most economical from the point of view of metabolism variants of reactions on arising up before an individual problem. Therefore, a preference gives oneself up to the prepared (by a model) decisions. ${ }^{12}$ Therefore, in the process of social evolution the extreme variants of intellect (individuals with a subzero intellect and genii) are cast aside. Mediocrity wins and propagates. A dull individual is integrated in any association much better, than man with the independent thinking.
(And to it experience testifies not only the USSR). Result: decline of mass of brain of man on the average on 300 gs for the last 150 years. ${ }^{12}$

\section{Conclusion}

So, a problem, meaningfulness of that is while realized by neither public nor science, stands before humanity- biological degradation of type of Homo sapiens. She shows up : by the speed-up rate of aging, decline of «amount» of health (to viability), epidemic of non-infection disease, decline of reproductive function, birth of weak posterity (these data are well known), decline of intellect and mass of cerebrum and other With every year this problem will be more intensified, showing up the decline of quality of human capital. From our point of view, there are all grounds to talk about a fourth demographic transition. If the first demographic transition was expressed in the changes of levels of birth-rate and death rate, second - in the changes of sexual behavior, organization of life of family and her forms, and the third demographic transition affected his composition, ${ }^{13}$ then a fourth demographic transition characterizes the decline of quality (to viability) of population. Thus, a social evolution enters into contradiction with a biological evolution, hampering biopower and population-intellectual progress. Thus, if evolutional processes in living flow very slowly, then degradation-far quicker. Is counteraction to the presented prospect possible? Radically changing nature of evolutional processes hardly will be succeeded, but to counteract to them, up to a point, it is possible. Getting to know nature of processes, man as creature socially the active will be able to manage them. And it is constrained, to our opinion, with the radical change of strategy of health protection - transition from strategy of management by illness to strategy of management by a health (by viability). Becomes obvious also, that no improvements of curatively diagnostic process in a health protection are not able radically to influence on the indexes of morbidity and death rate, because the low level of health (subzero thermodynamics stability) does not treat oneself pills. ${ }^{14-17}$ Only passing of basic part of population to the higher level of aerobic energy of functions (to efficiency of activity of mitochondria) is able to decide this problem. Essence of problem is obvious. Radically leaving from the nature in the process of social evolution, humanity already in earnest sawed a branch on that sits - decreased stability of the non-equilibrium thermodynamics system being the basis of the phenomenon of life. For the decision of problem creation of span-new direction of activity in a social sphere (obviously, out of sphere of health protection), having goals and tasks, is needed - to stop the loss of stability of thermodynamics non-equilibrium, - and methods of their decision. This must be the family «industry of health» (in addition to existent «industry of illness»), in that methods and facilities of renewal of thermodynamics non-equilibrium will be used due to perfection of function of mitochondria's. Introduction is very important in practice of health protection of diagnosis «insufficiency of physical activity» (International Classification of Iillnesses -10, class of XXI, Block of Z70 - Z76, Code of Z72.3), that now not used doctors. In fact, unfortunately, humanity did not think of more accessible and cheap way of decision of problem of «to charge» of mitochondria, except the physical training. But it is yet needed to tell everything and prove to the people. And they are people - still hope on pills and future hightech of improvement of human nature. We suppose that to humanity it is time to be thoughtful above a foregoing problem.

\section{Funding}

None. 


\section{Acknowledgments}

None.

\section{Conflicts of interest}

The authors have no conflicts of interest relevant to this article.

\section{Refrences}

1. Markov A. Evolution of man MGU. 2011;1(2).

2. Bauer E. Theoretical biology. Cross-Cultural Research. 1935:185-206

3. Apanasenko GL. Biological degradation of Homo Sapiens: ways of resistance Saarbrukken. Russia: Palmarium Academic Publishing; 2011.

4. Schrodinger Erwin. What is life? The physical aspect of the living cell UK: Cambridge Univ Press; 1944. p. 92.

5. Apanasenko G L. Evolution of bioenergetics and health of man. Petropolis. 1992.

6. Grigorijn G, Liabah E. Analysis of the adaptive reacting of cage on the deficit of energy. Lectures of Acad Sciences of Ukraine. 2008;11:45-150.

7. Hodgekiss A. Why 30 new 45 Were unhealthy 15 years OLDER parents age. Daily mail. 2010;10:4.

8. Chebotarev DFT. Speed-up senilism: reasons, diagnostics, prophylaxis and treatment. Med World. 2001;1(1):28-38.
9. Aspenes SF, Nilsen TIN, Skaug E A, et al. Peak Oxygen Up take and Cardiovascular Risk Factors in 4631Healthy Women and Men. Med Sci Sports Exerc. 2011;43(8):1465-1473.

10. Keteyian SJ, Brawner CA, DSavage P. Peak aerobic capacity predicts prognosis in patien ts with coronary heart disease. Am Heart $J$. 2008;156(2):292-300.

11. Osthus Ida Beata, Antonella Sgura, Francesco Berardinelli, et al. Telomere Length and LongTerm Endurance Exercise : Does Exercise Training Affect Biological Age? A Pilot Study. 2012;7(12):e52769.

12. Saveliev VV. Changeability and genius. M Conduct; 2012. p. 128.

13. Coleman D. Immigration and ethnic change in lowfertility countries: a third demographic transition. Population and Development Review. 2006;32(3):401-446.

14. Zotin AI. Biopower orientation of evolutional process of organisms. Pushino. 1981.

15. PNazaretian N. The Nonlinear future and problem of vital senses. Historical Psychology and Sociology of History. 2012;5(2):148-180.

16. Panov AD. Unity of socially biological evolution and limit of her acceleration. Historical Psychology and Sociology of History. 2008;1(2):25-48.

17. Myers J, Prakash M, Froelicher V, et al. Exercise capacity and mortality among men referred for exercise testing. N Engl J Med. 2002;346(11):793-801. 